\title{
Predictive significance of TMRPSS2-ERG fusion in prostate cancer: a meta-analysis
}

\author{
Chunjiao Song $^{1^{*}}$ (D) and Huan Chen ${ }^{2}$
}

\begin{abstract}
Background: Prostate cancer is a major malignancy in males. TMPRSS2-ERG is a high-frequency fusion gene expressed in prostate cancer and plays a vital role in carcinogenesis. Recent studies showed that TMPRSS2-ERG is a potential predictive biomarker for prostate cancer. However, the predictive value of TMPRSS2-ERG fusion is yet unclear.

Methods: A total of 76 relevant articles, published from 2015 to 2017, were obtained from PubMed, Web of Science, EMBASE, Scopus, the Cochrane Library, and CNKI databases to investigate the predictive significance of TMPRSS2-ERG fusion in prostate cancer. Pooled odds ratio (ORs) with 95\% confidence intervals (Cls) were calculated to estimate the correlation between TMPRSS2-ERG fusion gene and tumor features.

Results: The pooled or stratified analysis showed that the TMPRSS2-ERG fusion gene had a highly predictive potential. First, TMPRSS2-ERG fusion was associated with T-stage at diagnosis (T3-4 vs. T1-2 OR: 1.40; 95\% Cl 1.33-1.48) and metastasis (M1 vs. MO OR: 1.35; 95\% Cl 1.02-1.78) but not with biochemical recurrence or prostate cancer-specific mortality. Furthermore, the subgroup analysis found that the TMPRSS2-ERG fusion gene was correlated with Gleason (G) scores, and the fusion was common in prostate cancer with $G \leq 7$. Additionally, the meta-analysis demonstrated that the fusion was likely to occur in young patients (> 65 vs. $\leq 65$ OR: $0.68 ; 95 \% \mathrm{Cl} 0.52-0.89$ ), in patients with high PSA levels (> 10 vs. $\leq 10$ OR: 1.30; 95\% Cl 1.21-1.38), and in patients with peripheral involvement (positive vs. negative OR: $1.17 ; 95 \% \mathrm{Cl} 1.08-1.28$ ), while not associated with tumor volume. Finally, the subgroup analysis of different fusion types demonstrated that the deletion-type fusion was significantly associated with the malignant degree of prostate cancer (pooled OR: 5.67; 95\% Cl 2.85-11.28). Moreover, the deletion-type was common in Africa patients, followed by Caucasian patients, and no significant difference was observed in the incidence of different fusion types in the Asian population.
\end{abstract}

Conclusions: The meta-analysis findings suggested that the TMPRSS2-ERG fusion gene might be a predictive marker for prostate cancer patients, and might be valuable for assessing the characteristics of prostate cancer for individualized treatment and prognosis evaluation.

Keywords: TMPRSS2-ERG, Fusion gene, Prostate cancer, Meta-analysis

\section{Background}

Prostate cancer (PCa) is the most common non-skin cancer and a leading male malignancy worldwide. In 2017, 161,360 new cases were recorded, and 26,730 patients died of PCa in the USA [1]. According to the recent data of the National Center for Cancer, PCa has the highest

\footnotetext{
*Correspondence: chunjiaosong@163.com

${ }^{1}$ Medical Research Center, Shaoxing People's Hospital (Shaoxing Hospital, Zhejiang University School of Medicine), No. 568 Zhongxing Bei Road,

Shaoxing 312000, Zhejiang, People's Republic of China

Full list of author information is available at the end of the article
}

rate of occurrence of tumors in the urinary system since 2008 in China [2]. The morbidity rate was ranked sixth, while the mortality rate was ninth in all the male malignant tumors [2]. PCa is initially limited to the prostate and curable by a variety of therapeutic methods. However, about $23-40 \%$ of these patients with $\mathrm{PCa}$ would develop into CRPC (castration-resistant prostate cancer) or mCRPC (metastatic castration-resistant prostate cancer) after the primary treatment of $\mathrm{PCa}$, which is usually untreatable [3]. Metastatic PCa cells tend to metastasize 
to the liver, lung, bone, other visceral organs, as well as to the skin, leading to the death of the patient [4].

In the 1990s, the screening for PSA (prostate-specific antigen), widely used in clinical practice, led to a significant increase in PCa cases [5]. However, the PSA level was not specific for PCa and may fluctuate due to other prostatic diseases: inflammation, infection, or hyperplasia. Therefore, the diagnostic specificity of PSA was not high, which might lead to false-positives and overtreatment [6]. Moreover, 15\% of the males with low PSA levels would progress towards PCa [6]. As a result, the US Preventive Services Task Force recommended that PSA levels were not detected routinely, and PSA tests were only used for high-risk populations [7]. In addition, the diagnostic sensitivity of prostate needle biopsy was also low, with about $40 \%$ of the diagnostic results being false-negative, and only $2 \%$ of the PCa tissues could be sampled $[6,8]$. Thus, specific and precise biomarkers to accurately detect $\mathrm{PCa}$ and distinguish the different stages of $\mathrm{PCa}$ are yet to be elucidated.

In 2005, Tomlin et al. reported the first gene fusion of TMPRSS2 (transmembrane protease, serine 2) gene and ERG (ETS (erythroblast transformation-specific)-related gene), the most common form of $\mathrm{PCa}$-specific fusions [9]. Since then, the TMPRSS2-ERG fusion is the hotspot of the related studies on PCa. TMPRSS2-ERG fusion gene is specifically expressed in $\mathrm{PCa}$, involving the TMPRSS2 gene regulated by androgen and the oncogene $E R G$ that is a member of the ETS family of transcription factors. The fusion frequency of TMPRSS2-ERG was about $50 \%$ in Caucasian Americans (CA), 31\% in African Americans (AA) [10], and $18.5 \%$ in Asians [11]. The fusion gene may result in a high expression of $E R G$ by driving the androgen reaction element (ARE) of the TMPRSS2 gene [12], which plays a critical role in the regulation of cell growth, differentiation, and apoptosis [13]. This phenomenon indicates that TMPRSS2-ERG fusion may be a driver of $\mathrm{PCa}$ progression by affecting a series of downstream oncogenic effects. Thus, the TMPRSS2-ERG gene is considered to be an early event in the development of PCa. Furthermore, TMPRSS2-ERG gene fusion can be generated by chromosomal translocation or interstitial deletion [14, 15]. The frequency of translocation, deletion, and concurrence was $61.9 \%, 38.1 \%$, and $0 \%$ in CA patients, while $20 \%, 60 \%$, and $20 \%$ in AA cases, respectively [10].

TMPRSS2-ERG is an attractive biomarker as it can be accurately detected from various biological samples by several methods. For example, the gene rearrangement can be determined using fluorescence in situ hybridization (FISH) $[9,15]$, the expression level can be measured by polymerase chain reaction (PCR) [9], and the overexpression of ERG can be detected using immunohistochemistry (IHC) [16]. Moreover, a noninvasive diagnostic strategy was developed to clinically detect the fusion transcripts in patients' urine samples $[17,18]$. However, some studies on TMPRSS2-ERG fusion as the predictive biomarker for $\mathrm{PCa}$ based on different patient cohorts, detection methods, or data analysis platforms are yet controversial. Therefore, we systematically performed the meta-analysis to clarify the predictive accuracy of TMPRSS2-ERG in clinical PCa specimens.

\section{Materials and methods}

\section{Search strategy}

The meta-analysis was performed according to the standard guidelines for tumor biomarker studies. We searched PubMed, Web of Science, Embase, Scopus, the Cochrane Library, and Chinese National Knowledge Infrastructure (CNKI) databases to retrieve the relevant articles, published between 2005 and 2017, on the predictive value of TMPRSS2-ERG fusion gene in patients with PCa. The search strategy was a combination of Medical Subject Headings (MeSH) terminology and keywords as follows: ("prostate cancer" or "prostate carcinoma" or "prostate neoplasm" or "prostate tumor/tumor") and ("TMPRSS2-ERG" or "TMPRSS2-ETS") and ("marker" or "biomarker"). The selected articles were viewed carefully, and the reference lists were also screened to identify other eligible publications (Fig. 1). The literature search was completed on Dec 20, 2017.

\section{Inclusion and exclusion criteria}

According to the inclusion and exclusion criteria, the abstracts and the full texts of the relevant articles were screened for eligibility. A total of 197 primary studies and 43 additional records from reviews or meta-analysis were retrieved, and 76 publications were included in this meta-analysis (Fig. 1).

The studies selected for the meta-analysis were required to fulfill the following inclusion criteria: (1) TMPRSS2$E R G$ fusion status was identified. (2) All cases involved in these studies should have been verified by gold standard test (pathological confirmation for the diagnosis of PCa). (3) Sufficient data were reported to calculate the odds ratio (ORs) and the $95 \%$ confidence intervals (CIs). (4) The level of TMPRSS2-ERG was assessed in prostatic tissues or blood or urine samples.

The exclusion criteria for the study were as follows: (1) The studies were not original articles, such as reviews, letters, commentaries, erratums, and meta-analysis. (2) Data for TMPRSS2-ERG fusion gene were not sufficient for extraction. (3) Non-English or non-Chinese language. (4) Data were obtained from non-human samples or human cell lines. (5) Duplicate records. 


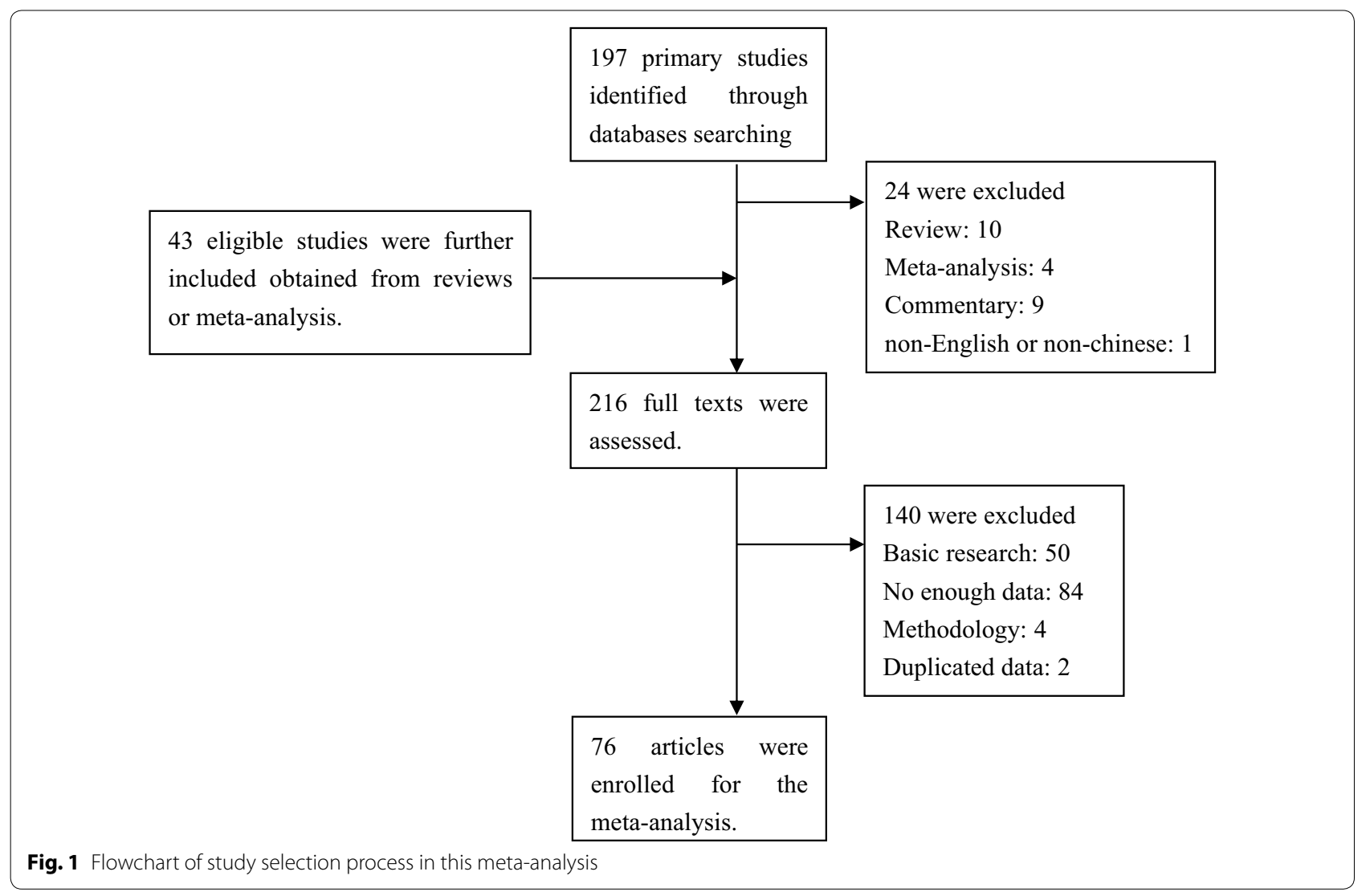

\section{Data extraction}

Data were extracted from all eligible studies using a standardized form to evaluate the association between the TMPRSS2-ERG fusion gene and PCa outcomes (tumor stage, Gleason (G) score, biochemical recurrence, lethal $\mathrm{PCa}$ ) and $\mathrm{PCa}$ clinical features (age at diagnosis, PSA level, tumor volume). In addition, the following information was collected: country, year of publication, the first author, patients' age, PSA level, tumor volume, the number of samples, detection strategy, and the diagnostic data (negative, positive, translocation-type, and deletion-type). Moreover, some articles reported the results of multiple subgroups, and hence, we extracted the data of each subgroup as an independent cohort to perform the meta-analysis.

\section{Quality assessment}

The quality of all included studies was assessed using Revman 5.3 software (Cochrane, London, UK). This software can be utilized to draw funnel plots to represent the publication bias, and these biased studies are distributed outside the edges. Simultaneously, the heterogeneity of the publications can be found by combining the $\mathrm{I}^{2}$ value (the inconsistency index) and P-value (Chi squared). If the $\mathrm{I}^{2}$ value is $>50 \%$ and the $\mathrm{P}$-value is $<0.1$, heterogeneity was ascribed in this analysis. Conversely, the heterogeneity of the articles was extremely low. Furthermore, to avoid the effects of heterogeneity, we performed subgroup analyses by classifying the included studies into several subgroups based on the methods, patients' races, and sample types.

\section{Statistical analysis}

The statistical analyses for the meta-analysis were performed using Revman 5.3 to calculate the overall predictive accuracy. Pooled ORs with $95 \%$ CIs and forest plots were used to assess the predictive role of TMPRSS2-ERG fusion gene in various stages of PCas. All P-values were two-tailed and $\mathrm{P}<0.05$ was considered to be statistically significant unless otherwise specified.

\section{Results}

\section{Characteristics of included studies}

According to our search strategy, a total of 197 primary studies and 43 additional studies were retrieved from PubMed, Web of Science, Embase, Scopus, the Cochrane Library, and CNKI databases. Figure 1 summarized the selection process for the systematic literature search. Finally, a total of 76 studies were included 
in this study after carefully reviewing the abstracts and full texts, and 42,997 cases $(34,219$ localized PCa, 360 metastatic PCa, 256 CRPC, 167 HGPIN (high-grade prostate intraepithelial neoplasia), $255 \mathrm{BPH}$ (benign prostate hyperplasia), and 7740 normal) were analyzed statistically based on different indices of the meta-analysis. Two studies were removed due to data duplication. Also, the following studies were excluded: review or meta-analysis or commentary $(n=23)$, studies belonging to basic research $(n=50)$, studies without sufficient relevant data $(n=84)$, methodological studies $(n=4)$, and non-English or non-Chinese articles $(n=1)$.

The primary characteristics of the 76 included studies were summarized in Additional file 1: Table S1 in the order of the published year and authors' surname. The publication period of these studies ranged from 2005 to 2017. In addition, some studies could be divided into several parts because they included multiple research cohorts. The data from these records were collected from all over the world, including 18 countries or regions except Africa. The dominant race in 60 studies was Caucasian, while 17 studies were executed in Asia. The fusion status and the expression level of TMPRSS2-ERG were detected using FISH $(\mathrm{n}=47)$, IHC $(\mathrm{n}=21)$, qRT-PCR $(\mathrm{n}=26)$, and transcription-mediated amplification (TMA) $(n=2)$ in prostate tissues $(n=72)$, while 1 study examined the blood samples and 5 studies utilized urine samples (Additional file 1: Table S1). In these studies, data from a total of 42,830 cases were available for the meta-analysis, with a minimum sample size of 19 and a maximum sample size of 11,152 patients. The diagnosis of patients with PCa was based on the pathological confirmation.

We calculated the pooled ORs and the $95 \%$ CIs to evaluate the association between TMPRSS2-ERG fusion and PCa outcomes: T-stage (T3-4 vs. T1-2), G (8-10 vs. 1-7), biochemical recurrence (positive vs. negative), and lethal PCa (positive vs. negative). Also, we assessed the association among age at diagnosis, PSA level, and tumor volume. Finally, we extracted the available data and performed subgroup analyses comparing the TMPRSS2-ERG-positive patients with deletion-type to other fusion types.

\section{TMPRSS2-ERG fusion and prostate cancer outcomes Tumor stage}

TNM (tumor node metastasis) is the staging of tumor in oncology, which was first presented by Pierre Denoix of France from 1943 to 1952. Then, American Joint Committee on Cancer (AJCC) and Union for International Cancer Control (UICC) gradually established the international staging criteria: (1) $\mathrm{T}$ (tumor) refers to the primary tumor lesion, with an increase in the tumor volume and the involved range of adjacent tissues, defined as T1-T4. (2) N (node) refers to the affected regional lymph nodes. When the lymph nodes are not affected, N0 is used. As the degree and scope of lymph node involvement is increased, N1-N3 are utilized. (3) M (metastasis) is defined as the tumor that is spread primarily through the blood channel; there is no distant metastasis represented by M0, and there are distant metastases in terms of M1.

The risk for the association between the TMPRSS2$E R G$ fusion and the PCa stages was estimated. In Fig. 2a, $\mathrm{d}$, we found that TMPRSS2-ERG fusion was more common in the T3-4 stages of PCa than in the T1-2 after excluding the two studies with heterogeneity Petterson et al. [19] and Zhou et al. [20] $(\mathrm{P}<0.01)$, and the pooled OR and 95\% CI was 1.40 (1.33-1.48). However, no statistical difference was detected in the analysis of $\mathrm{N}$ $(\mathrm{P}=0.26)$. Thus, it can be speculated that TMPRSS2ERG fusion was not associated with the adjacent lymph nodes, irrespective of whether they were affected (Fig. 2b, e). Moreover, a significant difference was detected in the comparison between $\mathrm{M} 1$ and M0 $(\mathrm{P}=0.04)$, the pooled OR and 95\% CI was 1.35 (1.02-1.78), respectively. In the M1 cases with distant metastases, TMRPSS2-ERG fusion was frequent (Fig. 2c, f).

\section{G score}

We carried out the subgroup analyses on the TMPRSS2ERG fusion gene in $\mathrm{PCa}$ with different $\mathrm{G}$ scores after excluding several studies, which might be the main source of heterogeneity. In the subgroup analysis classified by different detection methods (Fig. 3a, d), the data of FISH and IHC groups showed that TMPRSS2$E R G$ fusion was more frequent in $\mathrm{G} \leq 7 \mathrm{PCa}$ than in $\mathrm{G}>7 \quad(\mathrm{P}<0.01)$. Consequently, the $\mathrm{P}$-value of RT-PCR group was 0.11 , the pooled ORs and $95 \%$ CIs were 0.63 (0.52-0.75) in the FISH group, $0.80(0.61-1.05)$ in the RT-PCR group, and $0.79(0.68-0.91)$ in the IHC group, respectively. Moreover, the total $\mathrm{P}$-value was $<0.01$, and the total OR and 95\% CI was $0.73(0.66-0.81)$. The difference among FISH, RT-PCR, and IHC groups was not significant $\left(\mathrm{P}=0.14, \mathrm{I}^{2}=49.9 \%\right)$. The race subgroup analysis showed that TMPRSS2-ERG fusion was common in $\mathrm{G} \leq 7 \mathrm{PCa}$ (Fig. 3b, e), irrespective of Caucasian PCa $(\mathrm{P}<0.01)$ or in Asian PCa $(\mathrm{P}=0.08)$. The pooled ORs and 95\% CIs was $0.81(0.72-0.90)$ in the Caucasian group and $0.74(0.53-1.03)$ in the Asian group, respectively. The summarized P-value was $<0.01$, and the total OR and 95\% CI was 0.80 (0.72-0.89), and no difference was observed between the Caucasian and Asian groups $\left(\mathrm{P}=0.65, \mathrm{I}^{2}=0 \%\right)$. Also, the subgroup analysis of different sample types indicated that TMPRSS2-ERG fusion 
Fig. 2 Meta-analysis for prostate cancer outcomes. Forest plots show the pooled ORs and 95\% Cls of TMPRSS2-ERG fusion gene with corresponding heterogeneity statistics. Squares and horizontal lines correspond to the study-specific ORs and 95\% Cls; respectively. The area of the squares correlates with the weight of each enrolled study, and the diamonds represent the summary ORs and $95 \% \mathrm{Cls}$. Funnel plots are the assessment of potential publication bias. a Forest plot for the analysis of primary tumor; $\mathbf{b}$ forest plot for the analysis of adjacent lymph node; $\mathbf{c}$ forest plot for the analysis of metastasis; $\mathbf{d}$ funnel plot for primary tumor; (E) Funnel plot for adjacent lymph node; $\mathbf{f}$ funnel plot for metastasis; $\mathbf{g}$ forest plot for the analysis of biochemical recurrence; $\mathbf{h}$ forest plot for clinical recurrence; $\mathbf{i}$ forest plot for the analysis of prostate cancer-specific death; $\mathbf{j}$ funnel plot for the analysis of biochemical recurrence; $\mathbf{k}$ funnel plot for the analysis of potential publication bias of tumor-specific death was common in $\mathrm{G} \leq 7 \mathrm{PCa}[\mathrm{P}<0.01$, OR 95\% CI: 0.73 $(0.66-0.80)]$ (Fig. 3c, f). Only one study utilized urine samples, and the OR and 95\% CI was $1.82(0.66-5.03)$, indicating that TMPRSS2-ERG fusion was common in G > 7 PCa. This phenomenon might be attributed to the malignant $\mathrm{PCa}$ shedding the tumor cells into urine that can be detected. In addition, after carefully reviewing the full-texts, we confirmed that heterogeneity was primarily caused by 6 studies: Demichelis et al. [21], Attard et al. [22], Hu et al. [23], Sun et al. [24], Kulda et al. [25], and Liu et al. [26].

\section{Biochemical recurrence}

After removing a highly heterogeneous study (Barwick et al. [27]), the result did not present any association between TMPRSS2-ERG fusion and biochemical recurrence $(\mathrm{P}=0.37)$ as shown in Fig. $2 \mathrm{~g}$, j, and there was no correlation between the fusion status and clinical recurrence as shown in Fig. $2 \mathrm{~h}(\mathrm{P}=0.43)$. Moreover, the metaanalysis included 2556 patients who were followed up for biochemical recurrence (697 events) and 510 cases for clinical recurrence (109 events).

\section{Prostate cancer-specific death}

As shown in Fig. 2i, k, the meta-analysis included 211 males who were deceased due to $\mathrm{PCa}$ and 1947 males with PCa survived. However, there was no statistically significant difference in males with TMPRSS2-ERG fusion-positive tumors as compared to those with negative fusion ( $\mathrm{P}=0.49)$, and the pooled $\mathrm{OR}$ was 1.11 (95\% CI 0.82-1.50).

\section{Other clinical features Age at diagnosis}

Figure 4a, d demonstrated the pooled OR and 95\% CI, which was calculated to assess the association between the fusion status and age at diagnosis. The integrated

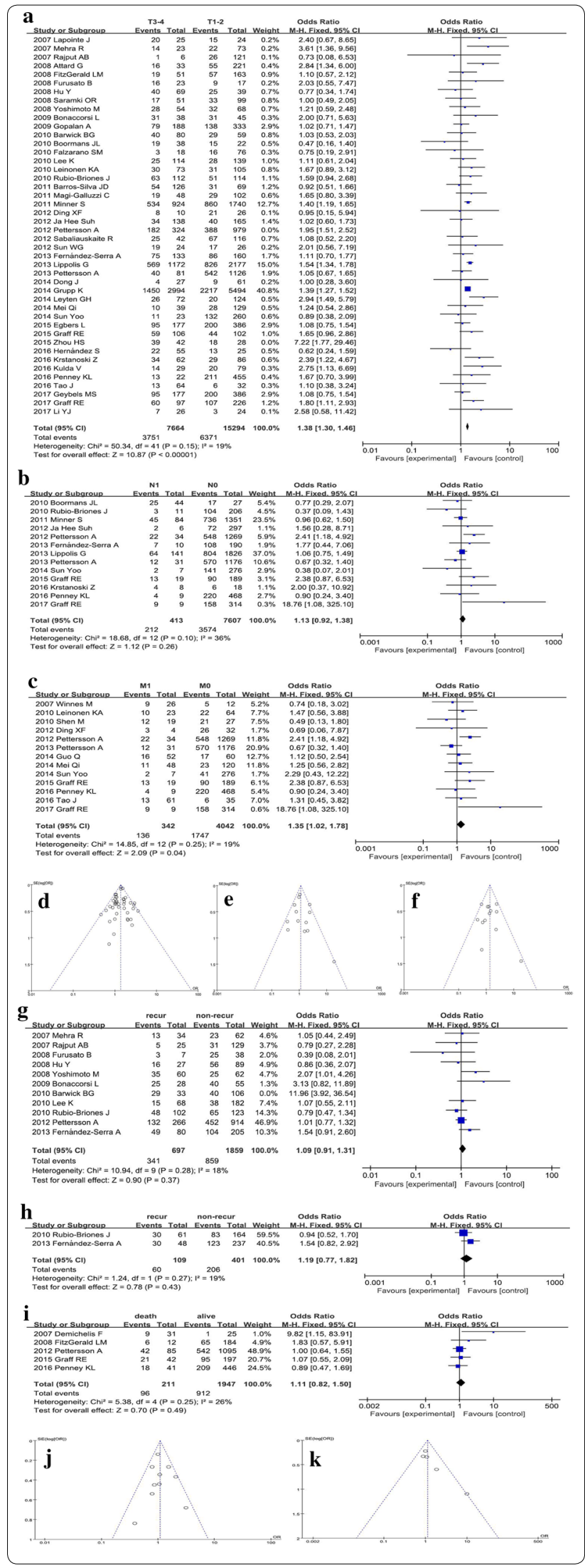


Fig. 3 Subgroup analysis for the Gleason score of prostate cancer. Forest plots of subgroup analyses stratified by detected methods, ethnicities, and sample types show TMRPSS2-ERG fusion gene with corresponding heterogeneity statistics. Squares and horizontal lines correspond to study-specific ORs and $95 \% \mathrm{Cls}$; respectively. The area of the squares correlates with the weight of each enrolled study, and the diamonds represent the summary ORs and 95\% Cls. Funnel plots represent the assessment of potential publication bias. The forest plots for a subgroup analysis stratified by detection methods, b subgroup analysis stratified by different races, $\mathbf{c}$ subgroup analysis stratified by sample types. The funnel plots for $\mathbf{d}$ subgroup analysis stratified by methods, e subgroup analysis stratified by races, $\mathbf{f}$ subgroup analysis stratified by sample types

result suggested that TMRPSS2-ERG fusion was associated with age $(\mathrm{P}<0.01)$, the pooled $\mathrm{OR}$ and $95 \% \mathrm{CI}$ was 0.68 (0.52-0.89). The TMPRSS2-ERG fusion was common in young males with $\mathrm{PCa}$ (age $\leq 65$ years), which was consistent with a previous study [28]. The intrinsic reason might be high levels of androgen in young patients that are likely to induce TMPRSS2-ERG fusion.

\section{Serum PSA level}

As shown in Fig. 4b, e, the pooled result implied that TMPRSS2-ERG fusion was associated with serum PSA level $(\mathrm{P}<0.01)$. The positive fusion was detected frequently in the PCa patients with a high level of PSA (>10 ng/mL), and the calculated OR and $95 \%$ CI was 1.30 (1.21-1.38). Among these included studies, Attard et al. [22] affected the result greatly, thereby indicating the high heterogeneity of the study.

\section{Tumor volume}

The detection of the fusion in urine was excluded using TMA method [29], and we found that TMPRSS2-ERG fusion was not associated with tumor size $(\mathrm{P}=0.40)$ (Fig. 4c). However, this phenomenon might be attributed to the little data extracted from these studies, and hence, additional studies are essential to confirm the correlation between TMPRSS2-ERG fusion and PCa volume.

\section{Margin invasion}

We analyzed the correlation between TMPRSS2-ERG fusion status and surgical margins. In Fig. 4f, g, the fusion was correlated to the involvement of the surgical margin $(\mathrm{P}<0.01)$, and the pooled OR and 95\% CI was 1.17 (1.081.28). Consequently, TMPRSS2-ERG fusion was positive in patients with surgical margin invaded by tumor cells.

\section{Perineural invasion}

Furthermore, we also discussed whether the fusion was correlated to the invasion of peripheral nerves. The meta-analysis result showed that a negative association

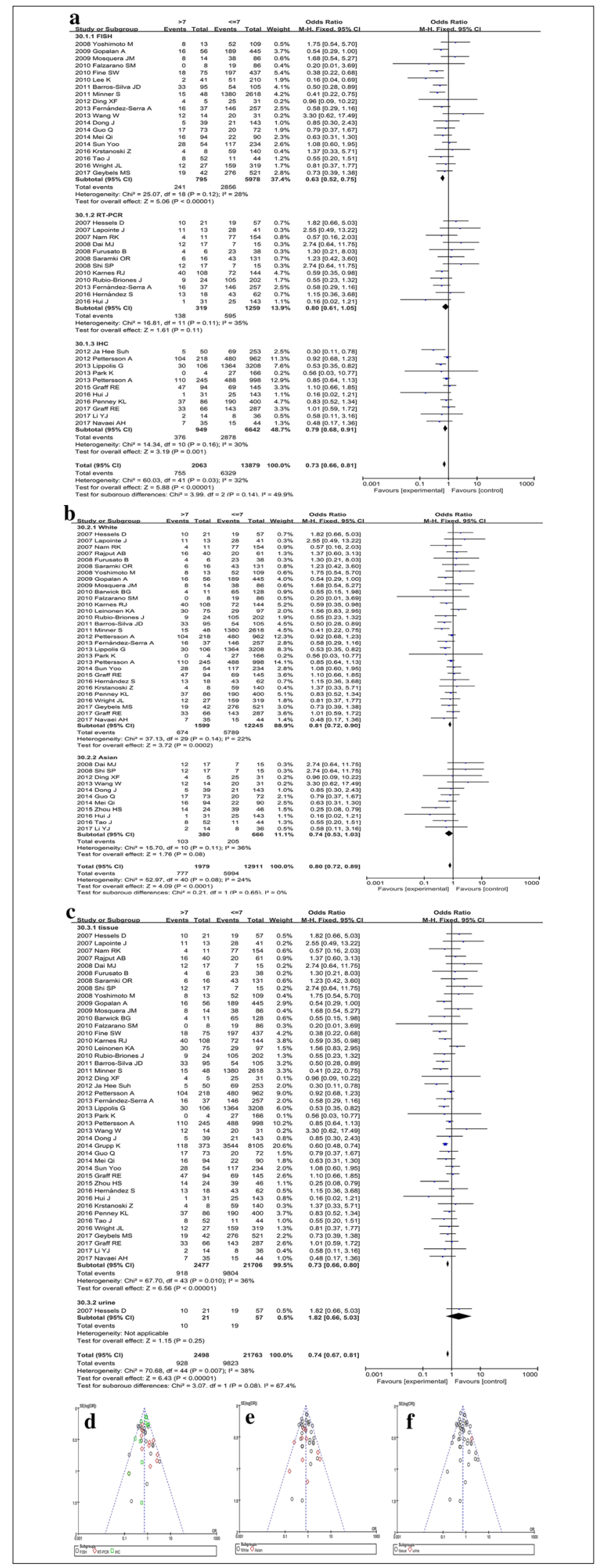


between the fusion status and perineural invasion $(\mathrm{P}=0.06)$ (Fig. 4h), which might be due to the little data in the study. Thus, we speculated a slight statistical significance; TMPRSS2-ERG fusion was likely to be detected in the cases of peripheral nerve involvement.

\section{Deletion-type fusion and prostate cancer}

Furthermore, we collected the data about the numbers of different fusion types in PCa tissues, including deletiontype fusion, translocation-type fusion, and amplificationtype. In addition, the subgroup analyses were shown in Fig. 5. Since the fusion subtypes of TMPRSS2-ERG must be detected using FISH in tissue samples; the subgroup analyses mainly involved the race subgroup (Fig. 5a, c), and the results did not show any obvious difference ( $\mathrm{P}=0.66)$ with respect to the Asians. On the other hand, in the Caucasian and African groups, deletion-type fusion was common $(\mathrm{P}<0.01)$. The pooled OR and 95\% CI was 1.77 (1.50-2.09) in the Caucasian group, while only one study provided complete data available for analysis in the African group with OR and 95\% CI 2.25 (0.637.97). The total P-value was $<0.01$, while the total OR and 95\% CI was 1.68 (1.43-1.97). The difference between the three groups was slightly significant $\left(\mathrm{P}=0.07, \mathrm{I}^{2}=63.1 \%\right)$, and the results were not consistent with those from previous studies [10, 11]. Moreover, after the removal of highly heterogeneous studies, only 5 performed in Asian population were considered. Of these, only 1 study on the African patients was included, and 19 studies provided the complete data for analysis in the Caucasian population. Thus, the conclusion might be incomplete, necessitating additional investigations.

Furthermore, the subgroup analyses elucidated the differences of TMPRSS2-ERG fusion types in metastatic PCa or CRPC groups (Fig. 5b, d). The meta-analysis results showed that the deletion-type fusion was common in metastatic PCa or CRPC $(\mathrm{P}<0.01)$, and the pooled ORs and 95\% CIs were 3.68 (1.43-9.48) and 9.41 (3.37-26.30), respectively. The summarized P-value was $<0.01$, and the total OR and $95 \%$ CI was 5.67 (2.8511.28) without a significant difference between metastatic PCa and CRPC groups $\left(\mathrm{P}=0.19, \mathrm{I}^{2}=42.5 \%\right)$. Only limited data were available for the subgroup analysis to confirm the predictive value of different fusion types, and hence, further studies with large sample size studies are imperative.

\section{Discussion}

Since TMPRSS2-ERG fusion was discovered in 2005, the specific fusion gene had been extensively studied as a potential predictive biomarker for PCa. However, the clinical value of TMPRSS2-ERG fusion is yet controversial because of different results as well as contrasting

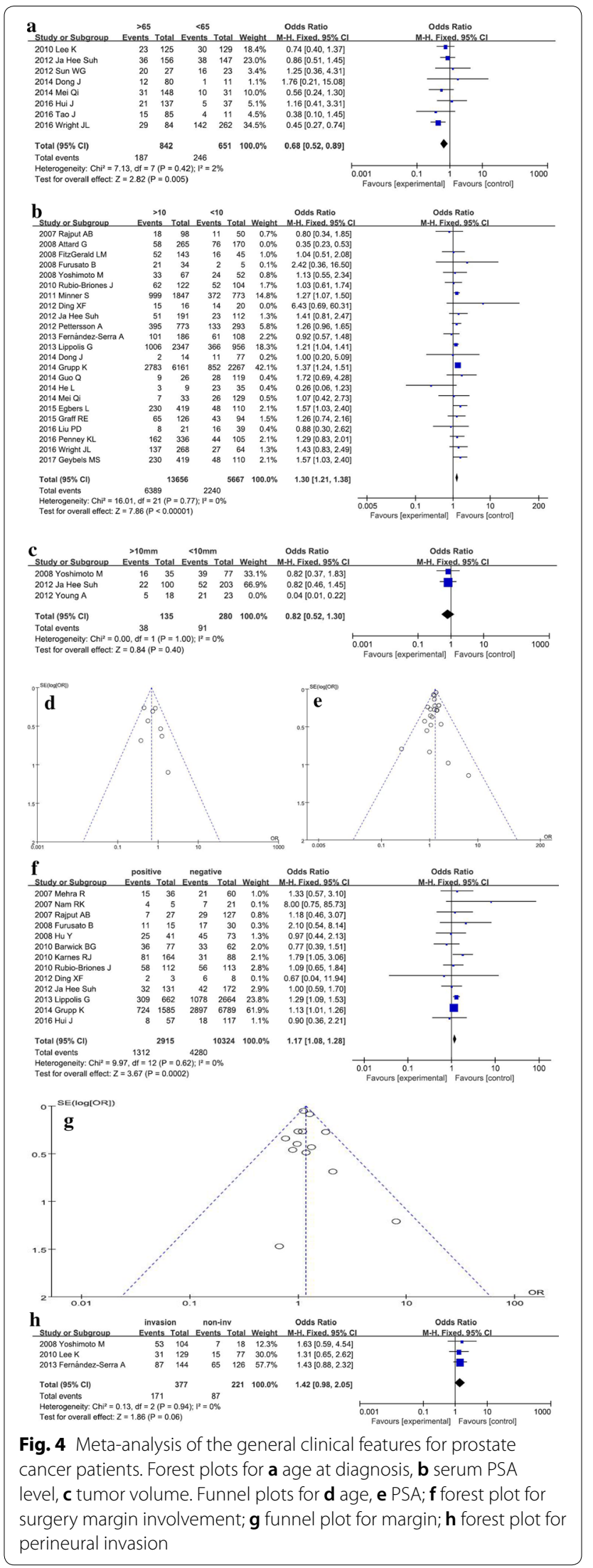


(See figure on next page.)

Fig. 5 The subgroup analysis assessed the association between TMPRSS2-ERG fusion subtypes and prostate cancer. Forest plots show the subgroup analyses of deletion-type fusion versus other fusion types. Squares and horizontal lines correspond to study-specific ORs and $95 \%$ Cls; respectively. The area of the squares correlates with the weight of each enrolled study, and the diamonds represent the summary ORs and $95 \%$ Cls. Funnel plots indicate the assessment of the potential publication bias. $\mathbf{a}$ forest plot for the subgroup analysis of different races; $\mathbf{b}$ funnel plot evaluating the heterogeneity for the subgroup analysis in different races; $\mathbf{c}$ forest plot for the subgroup analysis in metastatic PCa or CRPC; $\mathbf{d}$ funnel plot for the subgroup analysis in metastatic PCa or CRPC

conclusions. Herein, we investigated the application value of TMPRSS2-ERG fusion for PCa by meta-analysis of all relevant included studies. The meta-analysis demonstrated that ERG overexpression or positive fusion status was associated with advanced pathological characteristics of PCa. This phenomenon was inconsistent with the reports, wherein the frequency of TMPRSS2-ERG fusion was shown to be $50 \%$ in in situ carcinoma and decreased in malignant PCa [30]. Moreover, some studies reported a positive association between TMPRSS2$E R G$ fusion and clinicopathological features [15, 21, 22, 31-33], while other studies put forth a negative association [34-44]. In the systematic meta-analysis, our results demonstrated that TMPRSS2-ERG fusion was significantly associated with T-stages, metastasis, and G scores in PCa patients. Moreover, the fusion gene was common in young patients, in patients with high PSA levels, and in cases with peripheral involvement. The prevalence of the fusion was $52.4 \%$ in Caucasian cohorts, $36.3 \%$ in African cohorts, and $47.5 \%$ in Asian cohorts, which was different from the reports that the frequency of TMPRSS2ERG fusion was about 20\% in Asia [11]. The current meta-analysis did not find any association between $E R G$ overexpression or TMPRSS2-ERG-positive fusion and the risk of tumor recurrence; a similar result was found with PCa-specific death that was consistent with a previous meta-analysis [19]. The study also yielded a similarly negative result for tumor volume, while the study by Schaefer reported that $E R G$ overexpression was inversely correlated with the tumor size [45]. In addition, the subgroup analyses for the frequency of deletion-type of TMPRSS2-ERG fusion in different races and metastatic PCa or CRPC were conducted. Compared to the translocation or other patterns, the prognosis of PCa patients with deletion-type fusion was poor. Since the $2.8 \mathrm{Mb}$ region was located between TMPRSS 2 and ERG genes on chromosome 21 was lost in the deletion-type fusion, it was speculated that this region might contain critical tumor suppressors [46]. The current meta-analysis results exhibited that the incidence of deletion-type fusion was significantly higher in malignant PCa. Additionally, the deletion-type fusion was most common in African patients, followed by Caucasians, while no statistical difference was noted between deletion-type fusion and translocation-type fusion in Asian populations. However, limited data were collected from a limited number of appropriate studies, and hence, additional standardized data were required from large-sample multicenter trials to substantiate the current findings.

Notably, the high heterogeneity in these included studies was used to estimate the predictive accuracy of TMPRSS2-ERG fusion. The difference might be induced by the detection techniques, race of the study cohorts, the sample types, and the limited number of events in these studies. Among them, the results were highly heterogeneous in urine detections, which might be attributed to distinct urine components. Thus, the suspected negative cases should be examined multiple times to avoid misdiagnosis in the urine tests. Furthermore, subgroup analyses evaluated the diagnostic value of TMPRSS2-ERG fusion based on the different detection methods (FISH, RT-PCR, or IHC). In order to reduce the effects of the patients' ethnic groups with different genetic backgrounds, we classified the included studies into Caucasian, African, and Asian groups. Simultaneously, we also categorized the enrolled studies into three groups depending on the sample types (tissue, serum, or urine) to conduct subgroup analyses. The detection of the fusion gene in the tissues has been widely accepted by medical staff. However, the detection in serum or urine samples was attractive because it was noninvasive and convenient, which could be used to dynamically monitor the progress of the disease and the therapeutic effect at any time in the case of PCa patients.

Nevertheless, the meta-analysis has many merits. First, the current data from were recorded from the literature in strict accordance with inclusion criteria. Second, the qualities of the included literature were satisfactorily assessed by Revman 5.3 software. Third, we performed the subgroup analyses to effectively avoid the effects of heterogeneity and to explore the scope of application for TMPRSS2-ERG fusion as a predictive biomarker for PCa.

The meta-analysis also had some shortcomings. First, TMPRSS2-ERG positive fusion is only a subtype of PCa, and it cannot identify approximately $50 \%$ of the patients, which limits its clinical application. When the result of fusion gene detection is negative, the risk of $\mathrm{PCa}$ cannot be excluded. On the other hand, both TMPRSS2 and $E R G$ genes have multiple fusion partners, and these fusion variants are also associated with $\mathrm{PCa}$ outcomes 


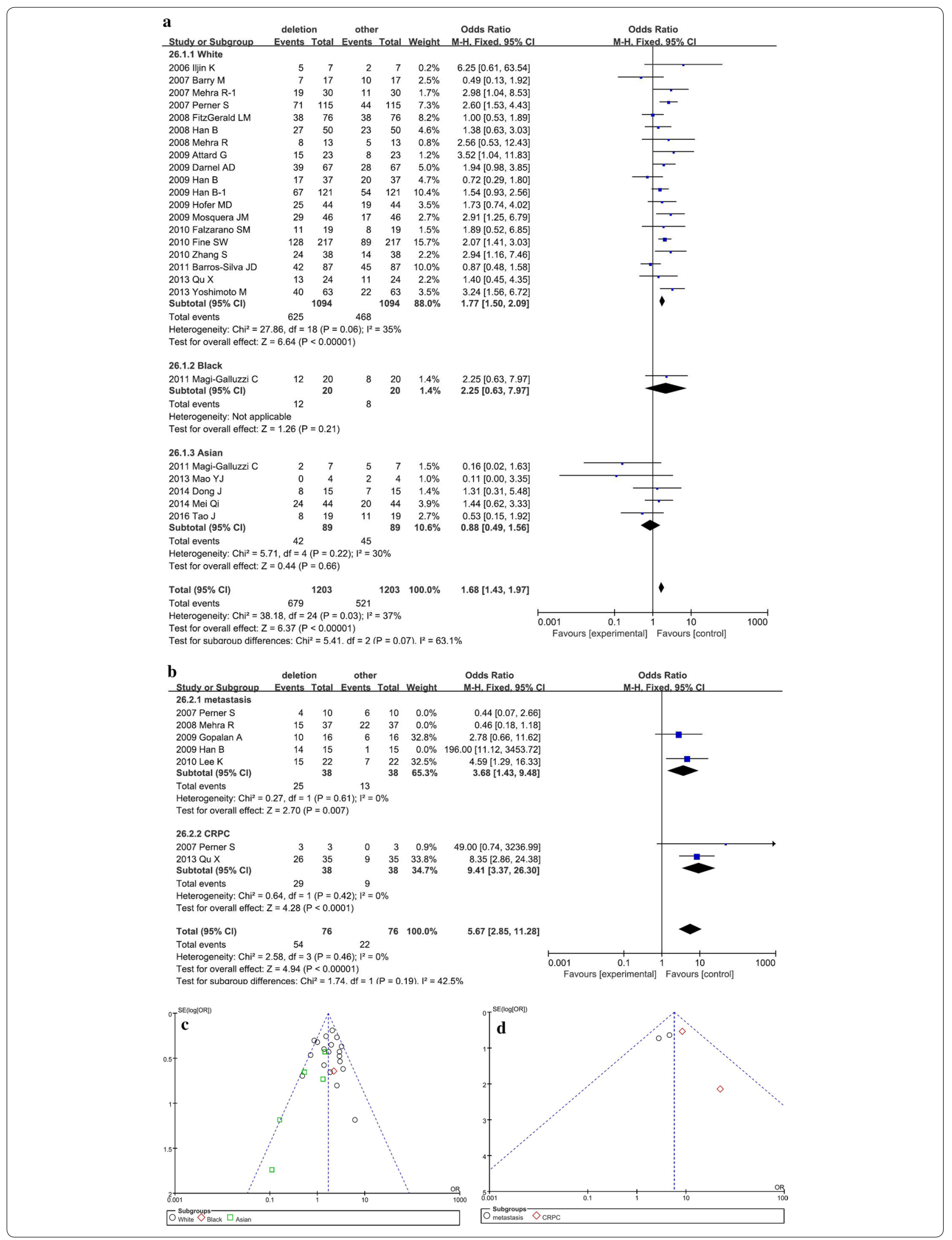


$[32,47,48]$. In the present meta-analysis, we evaluated the clinical value of TMPRSS2-ERG fusion at a maximal frequency in PCa. Strikingly, TMPRSS2-ERG fusion detection may be limited as the first-line detection, but due to the high specificity for $\mathrm{PCa}$, confirming the diagnosis and determining the subtype for personalized treatment is essential.

Second, some results of the meta-analysis were obtained from the limited available data after removing the several records because of high heterogeneity; for example, the analyses on metastatic PCa and CRPC, the analyses on clinical recurrence and lethal $\mathrm{PCa}$, and the analyses on tumor volume and peripheral involvement. Therefore, multicenter large-scale studies with high-quality are essential to confirm the current findings.

Third, some results did not exhibit a statistical significance after data consolidation and stratification analysis. While some were indistinguishable, others did not have sufficient data for analysis.

Finally, as there was no uniform cut-off value for $E R G$ expression level measured by RT-PCR or IHC, the evaluation of TMPRSS2-ERG fusion as a PCa biomarker was not accurate. The ERG score was utilized for further calculated based on the equation: TMPRSS2-ERG/ PSA $\times 100,000 . T M P R S S 2-E R G$ score was also assessed as a dichotomous variable that TMPRSS2-ERG-positive fusion was defined as copies $>10$. Both RT-PCR and IHC were indirect methods and could not evaluate the fusion status unlike FISH, which was a well-standardized and expensive method requiring only a small amount of tumor tissue. It could directly determine the fusion state and easily identify the other fusion types of TMPRSS2$E R G$ transcripts. However, FISH was only used in surgical tissues, and body fluid-based detection was not reported.

In summary, the application value of TMPRSS2-ERG fusion as a predictive factor for $\mathrm{PCa}$ was not elucidated, requiring additional data for substantiation of the hypothesis. In addition, the meta-analysis revealed that future studies should be more designed such as to consider the further application of the data. Finally, because TMPRSS2-ERG fusion occurred only in about $50 \%$ of the PCas [37], the combination of multiplex gene predictors' detection essentially replaced a single TMPRSS2-ERG to improve the predictive accuracy.

\section{Conclusions}

The meta-analysis carried out an omnidirectional analysis on the correlation between TMPRSS2-ERG fusion gene with various clinical characteristics of PCa. The TMPRSS2-ERG fusion was associated with stages, metastasis, and Gleason scores of PCa, while it was not associated with the involvement of the lymph node. In addition, the fusion status was not associated with tumor volume, $\mathrm{PCa}$ recurrence, or $\mathrm{PCa}$ specific death. Also, we found that TMPRSS2-ERG fusion was frequent in young patients, in patients with high PSA levels, and in patients with perineural involvement. Finally, the analysis of ratios of different fusion types in $\mathrm{PCa}$ cases demonstrated that the deletion-type fusion had the highest proportion in the black men with $\mathrm{PCa}$, followed by white, and in the Asian population, no difference was observed among the fusion subtypes. Consecutively, the deletion-type fusion was common in the malignant $\mathrm{mCRPC}$, which might be correlated to the loss of tumor suppressor genes located between TMPRSS2 and ERG genes.

\section{Additional file}

Additional file 1: Table S1. The main characteristics of the included studies.

\section{Abbreviations}

AA: African American; AJCC: American Joint Committee on Cancer; ARE: androgen reaction element; $\mathrm{BPH}$ : benign prostate hyperplasia; $\mathrm{CA}$ : Caucasian American; Cls: confidence intervals; CNKI: Chinese National Knowledge Infrastructure; CRPC: castration resistant prostate cancer; DASL: CDNA-mediated, annealing, selection, extension and ligation; ERG: ETS-related gene; ETS: erythroblast transformation-specific; FISH: fluorescence in situ hybridization; HGPIN: High Grade Prostate Intraepithelial Neoplasia; IHC: immunohistochemistry; MeSH: Medical Subject Headings; ORs: odd ratios; PCa: prostate cancer; PCR: polymerase chain reaction; PSA: prostate-specific antigen; qRT-PCR: quantitative real-time polymerase chain reaction; SPSS: Statistical Product and Service Solutions; TMA: transcription mediated amplification; TMPRSS2: transmembrane protease, serine 2; TNM: tumor node metastasis; UICC: Union for International Cancer Control.

\section{Authors' contributions}

SCJ and CH participated in the download of the relevant studies from public databases. $\mathrm{CH}$ performed the statistical analysis. SCJ participated in the design of the study and drafted the manuscript. Both authors read and approved the final manuscript.

\section{Author details}

${ }^{1}$ Medical Research Center, Shaoxing People's Hospital (Shaoxing Hospital, Zhejiang University School of Medicine), No. 568 Zhongxing Bei Road, Shaoxing 312000, Zhejiang, People's Republic of China. ${ }^{2}$ Zhejiang Institute of Microbiology (Key Laboratory of Microorganism Technology and Bioinformatics Research of Zhejiang Province), Hangzhou, Zhejiang, China.

\section{Acknowledgements}

The authors would like to acknowledge Dr. Guo to make constructive suggestions.

\section{Competing interests}

The authors declare that they have no competing interests.

\section{Availability of data and materials}

All data generated or analysed during this study are included in this published article and its additional information files. 
Consent for publication

Not applicable.

\section{Ethics approval and consent to participate}

Not applicable.

\section{Funding}

This study was supported by Zhejiang Provincial Science Technology Program of China (2013C33101), Zhejiang Medical Platform Program (2015RCA023), and Shaoxing Municipal Health and Family Planning Science and Technology Innovation Project (2017CX004).

\section{Publisher's Note}

Springer Nature remains neutral with regard to jurisdictional claims in published maps and institutional affiliations.

Received: 18 July 2018 Accepted: 31 October 2018

Published online: 12 November 2018

\section{References}

1. Siegel RL, Miller KD, Jemal A. Cancer statistics, 2017. CA Cancer J Clin. 2017;67(1):7-30. https://doi.org/10.3322/caac.21387 (Epub 2017 Jan 5)

2. Qi JL, Wang LJ, Zhou MG, Liu YN, Liu JM, Liu SW, Zeng XY, Yin P. Disease burden of prostate cancer among men in China, from 1990 to 2013. Zhonghua Liu Xing Bing Xue Za Zhi. 2016;37(6):778-82. https://doi. org/10.3760/cma.j.issn.0254-6450.2016.06.007 (Chinese).

3. Nadiminty N, Tummala R, Lou W, Zhu Y, Zhang J, Chen X, deVere White RW, Kung HJ, Evans CP, Gao AC. MicroRNA let-7c suppresses androgen receptor expression and activity via regulation of Myc expression in prostate cancer cells. J Biol Chem. 2012;287(2):1527-37. https://doi. org/10.1074/jbc.m111.278705 (Epub 2011 Nov 28).

4. Loberg RD, Logothetis CJ, Keller ET, Pienta KJ. Pathogenesis and treatment of prostate cancer bone metastases: targeting the lethal phenotype. J Clin Oncol. 2005;23(32):8232-41 (Review).

5. Center MM, Jemal A, Lortet-Tieulent J, Ward E, Ferlay J, Brawley O, Bray F. International variation in prostate cancer incidence and mortality rates. Eur Urol. 2012;61(6):1079-92. https://doi.org/10.1016/j.eururo.2012.02.054 (Epub 2012 Mar 8)

6. Chun FK, Epstein Jl, Ficarra V, Freedland SJ, Montironi R, Montorsi F, Shariat SF, Schröder FH, Scattoni V. Optimizing performance and interpretation of prostate biopsy: a critical analysis of the literature. Eur Urol. 2010;58(6):851-64. https://doi.org/10.1016/j.eururo.2010.08.041 (Epub 2010 Sep 4. Review)

7. Crawford ED, Andriole GL, Marberger M, Rittmaster RS. Reduction in the risk of prostate cancer: future directions after the prostate cancer prevention trial. Urology. 2010;75(3):502-9. https://doi.org/10.1016/j.urolo gy.2009.05.099 (Epub 2009 Dec 29. Review).

8. Haas GP, Delongchamps NB, Jones RF, Chandan V, Serio AM, Vickers AJ, Jumbelic M, Threatte G, Korets R, Lilja H, de la Roza G. Needle biopsies on autopsy prostates: sensitivity of cancer detection based on true prevalence. J Natl Cancer Inst. 2007;99(19):1484-9 (Epub 2007 Sep 25).

9. Tomlins SA, Rhodes DR, Perner S, Dhanasekaran SM, Mehra R, Sun XW, Varambally S, Cao X, Tchinda J, Kuefer R, Lee C, Montie JE, Shah RB, Pienta KJ, Rubin MA, Chinnaiyan AM. Recurrent fusion of TMPRSS2 and ETS transcription factor genes in prostate cancer. Science. 2005:310(5748):644-8.

10. Magi-Galluzzi C, Tsusuki T, Elson P, Simmerman K, LaFargue C, Esgueva R, Klein E, Rubin MA, Zhou M. TMPRSS2-ERG gene fusion prevalence and class are significantly different in prostate cancer of Caucasian, AfricanAmerican and Japanese patients. Prostate. 2011;71(5):489-97. https://doi. org/10.1002/pros.21265 (Epub 2010 Sep 28).

11. Ren S, Peng Z, Mao JH, Yu Y, Yin C, Gao X, Cui Z, Zhang J, Yi K, Xu W, Chen C, Wang F, Guo X, Lu J, Yang J, Wei M, Tian Z, Guan Y, Tang L, Xu C, Wang L, Gao X, Tian W, Wang J, Yang H, Wang J, Sun Y. RNA-seq analysis of prostate cancer in the Chinese population identifies recurrent gene fusions, cancer-associated long noncoding RNAs and aberrant alternative splicings. Cell Res. 2012;22(5):806-21. https://doi.org/10.1038/cr.2012.30 (Epub 2012 Feb 21).
12. Clinckemalie L, Spans L, Dubois V, Laurent M, Helsen C, Joniau S, Claessens F. Androgen regulation of the TMPRSS2 gene and the effect of a SNP in an androgen response element. Mol Endocrinol. 2013;27(12):2028-40. https://doi.org/10.1210/me.2013-1098 (Epub 2013 Oct 9).

13. Clark JP, Cooper CS. ETS gene fusions in prostate cancer. Nat Rev Urol. 2009;6(8):429-39. https://doi.org/10.1038/nrurol.2009.127 (Review).

14. Hermans $K G$, van Marion $R$, van Dekken $H$, Jenster $G$, van Weerden WM, Trapman J. TMPRSS2:ERG fusion by translocation or interstitial deletion is highly relevant in androgen-dependent prostate cancer, but is bypassed in late-stage androgen receptor-negative prostate cancer. Cancer Res. 2006;66(22):10658-63.

15. Perner S, Demichelis F, Beroukhim R, Schmidt FH, Mosquera JM, Setlur S, Tchinda J, Tomlins SA, Hofer MD, Pienta KG, Kuefer R, Vessella R, Sun XW, Meyerson M, Lee C, Sellers WR, Chinnaiyan AM, Rubin MA. TMPRSS2:ERG fusion-associated deletions provide insight into the heterogeneity of prostate cancer. Cancer Res. 2006;66(17):8337-41.

16. Park K, Tomlins SA, Mudaliar KM, Chiu YL, Esgueva R, Mehra R, Suleman K, Varambally S, Brenner JC, MacDonald T, Srivastava A, Tewari AK, Sathyanarayana U, Nagy D, Pestano G, Kunju LP, Demichelis F, Chinnaiyan AM, Rubin MA. Antibody-based detection of ERG rearrangement-positive prostate cancer. Neoplasia. 2010;12(7):590-8.

17. Bories PN, Younes P, Zerbib M, Denjean L, Popovici T, Cynober L, Delongchamps NB. TMPRSS2-ERG fusion transcripts in matched urine and needle rinse material after biopsy for the detection of prostate cancer. Clin Chem. 2013;59(1):245-51. https://doi.org/10.1373/clinchem.2012.192260 (Epub 2012 Oct 8)

18. Stephan C, Jung K, Semjonow A, Schulze-Forster K, Cammann H, Hu X, Meyer HA, Bögemann M, Miller K, Friedersdorff F. Comparative assessment of urinary prostate cancer antigen 3 and TMPRSS2:ERG gene fusion with the serum [-2]proprostate-specific antigen-based prostate health index for detection of prostate cancer. Clin Chem. 2013;59(1):280-8. https ://doi.org/10.1373/clinchem.2012.195560 (Epub 2012 Dec 4).

19. Pettersson A, Graff RE, Bauer SR, Pitt MJ, Lis RT, Stack EC, Martin NE, Kunz L, Penney KL, Ligon AH, Suppan C, Flavin R, Sesso HD, Rider JR, Sweeney C, Stampfer MJ, Fiorentino M, Kantoff PW, Sanda MG, Giovannucci EL, Ding EL, Loda M, Mucci LA. The TMPRSS2:ERG rearrangement, ERG expression, and prostate cancer outcomes: a cohort study and meta-analysis. Cancer Epidemiol Biomarkers Prev. 2012;21(9):1497-509. https://doi. org/10.1158/1055-9965.EPI-12-0042 (Epub 2012 Jun 26).

20. Zhou H, Zhu D, Luo H, Jiang S, Wang Z, Xie J, Liu A. Expression significance of TMPRSS2, ERG and ETV1 in prostate cancer. J Clin Exp Pathol. 2015;31(8):855-9.

21. Demichelis F, Fall K, Perner S, Andrén O, Schmidt F, Setlur SR, Hoshida Y, Mosquera JM, Pawitan Y, Lee C, Adami HO, Mucci LA, Kantoff PW, Andersson SO, Chinnaiyan AM, Johansson JE, Rubin MA. TMPRSS2:ERG gene fusion associated with lethal prostate cancer in a watchful waiting cohort. Oncogene. 2007;26(31):4596-9. Epub 2007 Jan 22. Erratum in: Oncogene. 2007;26(38):5692.

22. Attard G, Clark J, Ambroisine L, Fisher G, Kovacs G, Flohr P, Berney D, Foster CS, Fletcher A, Gerald WL, Moller H, Reuter V, De Bono JS, Scardino P, Cuzick J, Cooper CS, Transatlantic Prostate Group. Duplication of the fusion of TMPRSS2 to ERG sequences identifies fatal human prostate cancer. Oncogene. 2008;27(3):253-63 (Epub 2007 Jul 16).

23. Hu Y, Dobi A, Sreenath T, Cook C, Tadase AY, Ravindranath L, Cullen J, Furusato B, Chen Y, Thangapazham RL, Mohamed A, Sun C, Sesterhenn IA, McLeod DG, Petrovics G, Srivastava S. Delineation of TMPRSS2-ERG splice variants in prostate cancer. Clin Cancer Res. 2008;14(15):4719-25. https:// doi.org/10.1158/1078-0432.CCR-08-0531.

24. Sun WG, Xia L, Jiang LM, Yang WJ, Mo WF. Expression of TMPRSS2-ERG, AMACR and p63 in prostate cacinoma and their correlation Acta Universitatis Medicinalis Anhui 2012,47(11):1351-5.

25. Kulda V, Topolcan O, Kucera R, Kripnerova M, Srbecka K, Hora M, Hes O, Klecka J, Babuska V, Rousarova M, Benson V, Pesta M. predictive significance of TMPRSS2-ERG fusion gene in prostate cancer. Anticancer Res. 2016;36(9):4787-93.

26. Ganie MA, Marwaha RK, Nisar S, Faroogi KJ, Jan RA, Wani SA, Gojwari T, Shah ZA. Impact of hypovitaminosis D on clinical, hormonal and insulin sensitivity parameters in normal body mass index polycystic ovary syndrome women. J Obstet Gynaecol. 2016;36(4):508-12. https://doi. org/10.3109/01443615.2015.1103715 (Epub 2016 Jan 15). 
27. Barwick BG, Abramovitz M, Kodani M, Moreno CS, Nam R, Tang W, Bouzyk $M$, Seth A, Leyland-Jones B. Prostate cancer genes associated with TMPRSS2-ERG gene fusion and predictive of biochemical recurrence in multiple cohorts. Br J Cancer. 2010;102(3):570-6. https://doi.org/10.1038/ sj.bjc.6605519 (Epub 2010 Jan 12).

28. Steurer S, Mayer PS, Adam M, Krohn A, Koop C, Ospina-Klinck D, Tehrani AA, Simon R, Tennstedt P, Graefen M, Wittmer C, Brors B, Plass C, Korbel I, Weischenfeldt J, Sauter G, Huland H, Tsourlakis MC, Minner S, Schlomm T. TMPRSS2-ERG fusions are strongly linked to young patient age in lowgrade prostate cancer. Eur Urol. 2014;66(6):978-81.

29. Young A, Palanisamy N, Siddiqui J, Wood David P, Wei John T, Chinnaiyan Arul M, Kunju Lakshmi P, Tomlins Scott A. Correlation of urine TMPRSS2:ERG and PCA3 to ERG + and total prostate cancer burden. Am J Clin Pathol. 2012;138(5):685-96.

30. Tsourlakis MC, Stender A, Quaas A, Kluth M, Wittmer C, Haese A, Graefen M, Steurer S, Simon R, Korbel J, Weischenfeldt J, Huland H, Sauter G, Schlomm T, Minner S. Heterogeneity of ERG expression in prostate cancer: a large section mapping study of entire prostatectomy specimens from 125 patients. BMC Cancer. 2016;16:641. https://doi.org/10.1186/ s12885-016-2674-6.

31. Nam RK, Sugar L, Yang W, Srivastava S, Klotz LH, Yang LY, Stanimirovic A, Encioiu E, Neill M, Loblaw DA, Trachtenberg J, Narod SA, Seth A. Expression of the TMPRSS2:ERG fusion gene predicts cancer recurrence after surgery for localised prostate cancer. Br J Cancer. 2007;97(12):1690-5

\section{(Epub 2007 Oct 30)}

32. Wang J, Cai Y, Ren C, Ittmann M. Expression of variant TMPRSS2/ERG fusion messenger RNAs is associated with aggressive prostate cancer. Cancer Res. 2006;66(17):8347-51.

33. Yoshimoto M, Joshua AM, Cunha IW, Coudry RA, Fonseca FP, Ludkovski O, Zielenska M, Soares FA, Squire JA. Absence of TMPRSS2:ERG fusions and PTEN losses in prostate cancer is associated with a favorable outcome. Mod Pathol. 2008;21(12):1451-60. https://doi.org/10.1038/modpa thol.2008.96 (Epub 2008 May 23)

34. Saramäki OR, Harjula AE, Martikainen PM, Vessella RL, Tammela TL, Visakorpi T.TMPRSS2:ERG fusion identifies a subgroup of prostate cancers with a favorable prognosis. Clin Cancer Res. 2008;14(11):3395-400. https ://doi.org/10.1158/1078-0432.CCR-07-2051.

35. Lee K, Chae JY, Kwak C, Ku JH, Moon KC. TMPRSS2-ERG gene fusion and clinicopathologic characteristics of Korean prostate cancer patients. Urology. 2010;76(5):1268.e7-13. https://doi.org/10.1016/j.urology.2010.06.010 (Epub 2010 Aug 30)

36. Leinonen KA, Tolonen TT, Bracken H, Stenman UH, Tammela TL, Saramäki OR, Visakorpi T. Association of SPINK1 expression and TMPRSS2:ERG fusion with prognosis in endocrine-treated prostate cancer. Clin Cancer Res. 2010;16(10):2845-51. https://doi.org/10.1158/1078-0432.CCR-09-2505 (Epub 2010 May 4).

37. Gopalan A, Leversha MA, Satagopan JM, Zhou Q, Al-Ahmadie HA, Fine SW, Eastham JA, Scardino PT, Scher HI, Tickoo SK, Reuter VE, Gerald WL. TMPRSS2-ERG gene fusion is not associated with outcome in patients treated by prostatectomy. Cancer Res. 2009;69(4):1400-6. https://doi. org/10.1158/0008-5472.CAN-08-2467 (Epub 2009 Feb 3).

38. Lapointe J, Kim YH, Miller MA, Li C, Kaygusuz G, van de Rijn M, Huntsman DG, Brooks JD, Pollack JR. A variant TMPRSS2 isoform and ERG fusion product in prostate cancer with implications for molecular diagnosis. Mod Pathol. 2007;20(4):467-73 (Epub 2007 Mar 2).

39. Rostad K, Hellwinkel OJ, Haukaas SA, Halvorsen OJ, Øyan AM, Haese A, Budäus L, Albrecht H, Akslen LA, Schlomm T, Kalland KH. TMPRSS2:ERG fusion transcripts in urine from prostate cancer patients correlate with a less favorable prognosis. APMIS. 2009;117(8):575-82. https://doi.org/10.11 11/j.1600-0463.2009.02517.x.

40. Hofer MD, Kuefer R, Maier C, Herkommer K, Perner S, Demichelis F, Paiss T, Vogel W, Rubin MA, Hoegel J. Genome-wide linkage analysis of TMPRSS2ERG fusion in familial prostate cancer. Cancer Res. 2009;69(2):640-6. https ://doi.org/10.1158/0008-5472.CAN-08-2008.

41. Rubio-Briones J, Fernández-Serra A, Calatrava A, García-Casado Z, Rubio L, Bonillo MA, Iborra I, Solsona E, López-Guerrero JA. Clinical implications of TMPRSS2-ERG gene fusion expression in patients with prostate cancer treated with radical prostatectomy. J Urol. 2010;183(5):2054-61. https:// doi.org/10.1016/j.juro.2009.12.096 (Epub 2010 Mar 19).

42. Toubaji A, Albadine R, Meeker AK, Isaacs WB, Lotan T, Haffner MC, Chaux A, Epstein JI, Han M, Walsh PC, Partin AW, De Marzo AM, Platz EA, Netto GJ. Increased gene copy number of ERG on chromosome 21 but not TMPRSS2-ERG fusion predicts outcome in prostatic adenocarcinomas. Mod Pathol. 2011;24(11):1511-20. https://doi.org/10.1038/modpa thol.2011.111 (Epub 2011 Jul 8).

43. Minner S, Enodien M, Sirma H, Luebke AM, Krohn A, Mayer PS, Simon R, Tennstedt P, Müller J, Scholz L, Brase JC, Liu AY, Schlüter H, Pantel K, Schumacher U, Bokemeyer C, Steuber T, Graefen M, Sauter G, Schlomm T. ERG status is unrelated to PSA recurrence in radically operated prostate cancer in the absence of antihormonal therapy. Clin Cancer Res. 2011;17(18):5878-88. https://doi.org/10.1158/1078-0432.CCR-11-1251 (Epub 2011 Jul 26).

44. Darnel AD, Lafargue CJ, Vollmer RT, Corcos J, Bismar TA. TMPRSS2-ERG fusion is frequently observed in Gleason pattern 3 prostate cancer in a Canadian cohort. Cancer Biol Ther. 2009;8(2):125-30 (Epub 2009 Feb 4).

45. Schaefer G, Mosquera JM, Ramoner R, Park K, Romanel A, Steiner E, Horninger W, Bektic J, Ladurner-Rennau M, Rubin MA, Demichelis F, Klocker $H$. Distinct ERG rearrangement prevalence in prostate cancer: higher frequency in young age and in low PSA prostate cancer. Prostate Cancer Prostatic Dis. 2013;16(2):132-8. https://doi.org/10.1038/pcan.2013.4 (Epub 2013 Feb 5)

46. Dong J, Xiao L, Sheng L, Xu J, Sun ZQ. TMPRSS2:ETS fusions and clinicopathologic characteristics of prostate cancer patients from Eastern China. Asian Pac J Cancer Prev. 2014;15(7):3099-103.

47. Hermans KG, Boormans JL, Gasi D, van Leenders GJ, Jenster G, Verhagen PC, Trapman J. Overexpression of prostate-specific TMPRSS2(exon 0)-ERG fusion transcripts corresponds with favorable prognosis of prostate cancer. Clin Cancer Res. 2009;15(20):6398-403. https://doi.org/10.1158/10780432.CCR-09-1176 (Epub 2009 Oct 13).

48. Shah RB, Chinnaiyan AM. The discovery of common recurrent transmembrane protease serine 2 (TMPRSS2)-erythroblastosis virus E26 transforming sequence (ETS) gene fusions in prostate cancer: significance and clinical implications. Adv Anat Pathol. 2009;16(3):145-53. https://doi. org/10.1097/PAP.0b013e3181a12da7 (Review).

Ready to submit your research? Choose BMC and benefit from:

- fast, convenient online submission

- thorough peer review by experienced researchers in your field

- rapid publication on acceptance

- support for research data, including large and complex data types

- gold Open Access which fosters wider collaboration and increased citations

- maximum visibility for your research: over 100M website views per year

At BMC, research is always in progress.

Learn more biomedcentral.com/submissions 